\title{
Obstructive urolithiasis in ruminants - A review
}

D. M Makhdoomi and Mohsin A Gazi

Faculty of Veterinary Sciences and Animal Husbandry

Sher-e-Kashmir University of Agricultural Science and Technology, Kashmir, India

Corresponding author: D. M Makhdoomi, email:dmmakhdoomi@gmail.com

Received: 27-07-2012, Accepted: 11-08-2012, Published online: 19-01-2013

How to cite this article:

Makhdoomi DM and Gazi MA (2013) Obstructive urolithiasis in ruminants - A review, Vet. World 6(4): 233-238, doi: 10.5455/ vetworld.2013.233-238

\begin{abstract}
Obstructive urolithiasis is the retention of urine subsequent to lodgment of calculi anywhere in the urinary conduct from up to urethral orifice. The disease results in heavy economic losses to the livestock industry as it is attributed the fifth most prevalent cause of death in feedlot. Obstructive urolithiasis is a serious, potentially fatal condition, most commonly causing symptoms in castrated male animals, but also occurring in breeding males. Many surgical approaches and techniques for the diagnosis and the treatment of the disease have been described with their relative merits and demerits in the literature.
\end{abstract}

Key words: calculi, obstruction, steer, urolithiasis

\section{Incidence}

Urolithiasis affects both sexes, but urinary blockade is a major problem only in males. Steers are most commonly affected by the obstructive form of the disease because of the anatomical confirmation of their urinary tract. Urethral obstructon has been extensively reported in ruminant species [1] and is a common problem encountered in male sheep, goat and cattle [2]. Among the bovine species, buffalo calves, $81.25 \%$ suffered more frequently than the cow calves $9.82 \%$ and bullocks $8.92 \%$ [3]. The calculi are mostly found in urinary bladder, but can also occur in renal pelvis \& urethra [4]. The calculi dislodged from bladder may get trapped in narrow male urethra, Sigmoid flexure [5] or at preputial opening. Urinary obstruction may also occur due to cystitis.

An overall incidence of 5.04 percent in animals has been reported in India [6]. The species wise incidence has been reported as: goats 49.83 percent, cattle 32.87 percent, dogs 14.53 percent, horses 1.38 percent, sheep 1.04 percent and cats 0,34 percent [6]. From Kashmir valley an overall incidence of 12 percent in cases of obstructive urolithiasis in cattle calves has been reported [7]. Incidence of urolithiasis as high as $13.4 \%$, in Anantnag, $12.6 \%$, Budgam 11.9\%, Pulwama $6.9 \%$, and Srinagar $10.5 \%$ in male cow calves [8]

\section{Etiology}

The etiology is complex and multifactorial. Although urolithiasis is known to have numerous predisposing etiology factors [9], but exact mechanism of stone formation and growth is not fully known.

Urinary calculi formation usually results from a combination of various physiological, nutritional and management factors. It may occur due to excessive or imbalanced intake of minerals [10] in feedlots while fattening cattle receive rations high in cereal grain and oil meals. These feedstuffs have high levels of phosphorous and magnesium but relatively low level of calcium and potassium predispose to disease condition [9]. A calcium phosphorous imbalance results in high urinary phosphate excretion which is an important factor in the genesis of phosphate calculi [11]. Numerous additional factors have been incriminated as contributing causes of the development of phosphate calculi with resultant obstructive urolithiasis in cattle. These include heavy concentrate-low roughage diets, limited intake or deprived of water, dehydration, urine alkalinity, mineralized artesian water, alkaline water supplies, excess of sodium bicarbonate in diet, vitamin imbalance e.g hypovitaminosis and hypervitaminosis and high protein rations $[9,12]$. Less frequently uroliths composed of silica, carbonates or oxalate. Livestock grazing in pastures containing large quantities of oxalates, estrogen or silica are prone to develop these types of calculi [13]. Urolithiasis in castrated beef cattle has been reported to be associated with diethylstilbestrol implants [14]. Geographical and seasonal influences play an important role for range herds in semi-arid areas. In addition, the anatomy of the male ruminant urinary tract also contributes due to the potential narrowness of the passage and tortuous route. The sigmoid flexure is a common site for uroliths to lodge in all ruminant species [14]. Uroliths may also be fount on lesser occasion at the ischial arch. In small ruminants the urethral process is an extremely common site for uroliths to lodge [15].

\section{Pathophysiology}

Despite sophisticated surgical techniques and various supportive treatments prognosis of urolithiasis in bovine still remains unpredictable $[16,17]$. Formation of calculi and development of urolithiasis is a complex process and occurs in aseries of phases from 
formation of nidus ,concencrtation of urine and lastly the precipitation of various salts from urine. Formation of urinary calculi is dependent on supersaturation of urine with soluble ionized minerals. Crystal formation occurs when the inhibitory capacity of mucopolysaccharides, ions, and organic acids is exceeded. [18, 19]. A variety of risk factors exist for the development of uroliths in ruminant species. Decreased salt or water intake, urinary stasis, urinary tract infection, high urine $\mathrm{pH}$ [struvite, calcium phosphate, and calcium carbonate stones], which could however be achieved to a $\mathrm{pH}<6.5$ in goats [20] by dietary supplimentation of ammonium chloride. Vitamin A deficiency, and high estrogen intake have all been implicated as risk factors [21]. The infectiuos stones, Obligate urease-producing bacteria [>98\%] Proteus spp. urease-producing bacteria, Providencia rettgeri, Morganella morganii Corynebacterium urealyticum, Ureaplasma urealyticum and facultative urease producing bacteria Enterobacter gergoviae, Klebsiella spp., Providencia stuartii and Staphylococcus spp. have been reported to act as nidus in iniciation of calculi formation. Renal calculi are formed when the urine is supersaturated with salt and minerals such as calcium oxalate, struvite [ammonium magnesium phosphate], uric acid and cystine [22]. Cystine is poorly soluble in urine and crystallizes spontaneously within the physiological range of urine $\mathrm{pH}$. 6.0 and limit of solubility is $1.33 \mathrm{mmol} / \mathrm{L}$. The main therapeutic option for avoiding cystine crystalization is to maintain urine $\mathrm{pH}$ above 7.5 to improve cystine solubility and to ensure appropriate hydration with a minimum of 3.5 L/day [23]. Stones formed by crystal ized compounds of the drugs, causing crystalization of urine like Amoxicillin/ampicillin, Ceftriaxone, Ciprofloxacin, Ephedrine, Indinavir, Magnesium trisilicate and Sulfonamide result in unfavorable changes in urine composition under drug therapy [24].

In an attempt towards in-depth understanding of the phenomenon, investigation into pathophysiological changes from onset of the urolithiasis workers have developed varieties of experimental models of urolithiasis but they could not fetch much about the aspect other than damages restricted to lower urinary conducts. Studies on urodynamics during obstructive uropathy revealed damage to bladder wall, ureters, kidneys and urine peritonitis [25]. Casts and cells are also observed in animals having long standing obstruction of urethra. This is due to pathological changes that commence as a result of accumulation of urine inside the bladder [26]. In the early stages of urinary obstruction, the animal attempts to urinate and the tail may be seen to have a pumping action. As the bladder continues to distend, the animal may kick at its abdomen, wring its tail and lie down frequently. Continued obstruction leads to perforation of the urethra of the penis and/or rupture of the urinary bladder. Upon perforation or rupture, the animal may not show signs of discomfort any more [27]. Even with appropriate treatment urethral stricture or hydronephrosis may present long term complica- tions. Clinical signs will vary depending on the duration of obstruction, the site of obstruction, and whether a rupture has occurred [28]. Cosequent to localization of calculi in urethral tract. Complete blockage of the urinary flow from a kidney decreases glomerular filtration rate and, if it persists for more than 48 hours, may cause irreversible renal damage [29].

There is an increased intracystic, and intra urethral pressure developing in pace with duration of obstruction upto 64 to 72 hours of obstruction which declines after re-establishing the free urine flow/ or the seepage of urine from bladder. The increased retrograde pressure built up in the ureter leads to failure of vesico-ureteral reflux and with resultant mild, moderate to degree of nephropathy depending upon duration of obstruction. [25]. under clinical situations this retrograde pressure nephropathy seems to set at 48 hours of post-obstructive period and thereafter. But whether it could be evidenced before 48 hours of urethral obstruction can not be ascertained. obstruction of urine flow wheather located in renal pelvis ureter, urinary bladder or urethra causes back pressure induced by the obstructing urine flow impaired the mechanisim of tubular reabsorption and tubular secretion, significantly reduced glomerular filteration rate and renal blood flow, thus post renal obstructive uropathy and uraemia develops either due to obstruction to urine flow or destruction of renal parenchyma or both [1]. Because of retrograde pressure consequent to obstruction of urethra, renal pelvis gets enlarged at the cost of renal parenchyma and the exclusion of the blood flow due to increased pressure inside the inexpansible renal capsule which leads to a disuse atrophy [9].

Due to continuous formation of urine and its accumulation in the bladder subsequent to urethral obstruction the bladder gets distended. The increasing pressure and distended stretching of bladder wall resulted in inflammation, pressure ischaemia, devitalization, thinning, trabeculae formation, herniation of mucosa through the musculature of the urinary bladder leading to seepage or voiding of whole of the stagnated urine into the the peritoneal cavity resulting in uroperitoneum and peritonitis , more so in bovine urolithiasis very little is documented about uropathy. The data regarding it is available mostly in dogs or human beings. There occurs a secondary damage to kidney caused by a retrograde intracystic pressure in complete urinary obstructed cases resulting in the uraemia [25].

\section{Clinical signs}

The clinical signs associated with urolithiasis depend upon the degree of obstruction to free flow of urine. Severity of surrounding tissue reactions [25]. The major clinical signs reported during the onset of urolithiasis include anorexia, suspended rumination and decreased water intake. Animals suffering from partial obstruction dribble blood tinged urine after prolonged, painful attempts of urination, as the disease 
progress the symptoms depicted are abdominal bilateral distention, tenesmus, colic, and weight shifting, and grinding of teeth, urethral pulsation [9] and tendency of rectal prolapsed. Animals may have an arched stance, tread their feet, swish the tail, or kick at their belly. Urolithiasis should always be near the top of the differential list in male ruminants with signs of colic, particularly in sheep and goats. Stranguria, anuria, oliguria, hematuria, mineral deposits on the urethral hairs, uremic odor to the breath, urinary bladder distention and pulsations of the pelvic urethra may also be present. Less specific signs include rectal prolapse, rumen stasis, tachycardia and tachypnea. There is severe damage to the bladder and urethral mucosa by uroliths which leads to haematuria [30], oligouria and dysuria [9]. In terminal stages, the temperature start decreasing, due to retention of metabolic wastes and their reabsorption results in toxaemia [9]. Complete urethral obstruction results in death due to uraemia [13].

\section{Laboratory findings}

The available literature regarding haematobiochemical alterations during the phase of urolithiasis are dynamic. There is haemoconcentration due to dehydration as a result of fluid leakage across peritoneum and neutrophilia. The increase in PCV, TLC and TEC was also reported [31,30]. An increase in nuetrophil count and leuckocytosis is due to stress [32,33]. The most prominent and descriptive meaure of uraemia due to urolithiasis is Blood urea nitrogen [BUN], that can be used as an index of uraemia because of its dependability and simplicity in assessment [9]. There is rising trend of BUN [25,32] during urolithiasis from the normal values in bovine which stand estimated so for by different workers as in bullocks, $19.71 \mathrm{mg} \%$ and in calves $7.27 \mathrm{mg} \%$. During the phase of obstruction BUN levels are much higher ranging from 136.0-420 $\mathrm{mg} \%$. There has been a progressive increase in BUN levels at the rate of $53 \mathrm{mg} \%$ per day in an induced obstruction in Bullocks, however BUN above 200 $\mathrm{mg} \%$ are reported to be detrimental for the surgical treatment. There occurs a regulation of BUN through saliva in ruminants; otherwise the values of urea nitrogen would be much higher in blood than are estimated [8].

A creatinine test is used to measure the amount of creatine in a patient's blood or urine. This helps determine how well the kidneys are able to filter small molecules, such as creatine out of blood. Healthy individuals usually have about 0.8-1.4 milligrams of creatine per deciliter of blood. Elevated levels indicate kidney disease. As the disease progresses there is increase in the levels and creatinine [25,32]. As the anorexia progresses there is severe muscle break down with resultant hypoprotinemia elevated alkaline phosphate. Possible tissue hypoxia following retained urine with breakdown of high energy phosphate compounds cause hyperphosphataemia which serve as a more reliable index under clinical situations.

As the clinical manifestation of the disease advances and the animal turns anorexic there occurs a decrease in plasma glucose levels [30]. Advanced obstructive nephropathy, poor renal perfusion, uroperitoneum, metabolic acidosis and hemolysis results in Hyperkalemia. The cardiotoxic effects of hyperkalemia may be excerbated by concurrent hyponatremia or hypocalcemia. A consequent digestive disorder results in Hypochloraemia due to sequestration of chloride ions in the digestive tract. There occurs a retention of chloride in the gut to compensate for large increase in potassium ions, decrease intake of chloride following anorexia, diffusion of chloride to peritoneal cavity [32] and total body water expansion relative to total body chloride. Thus, in urolithiasis there is derangement of acid-base balance and electrolyte. Majority of the animals develop alkalosis but metabolic acidosis have also been recorded [5]. Uraemia due to Urolithiasis is a threat to survival of animals. As the animal start taking normal feed and water after initiation of treatment, $\mathrm{PCV}, \mathrm{Hb}, \mathrm{TEC}$ shows slight fall probably due to rehydration and return of the Creatinine and BUN levels near normal.

\section{Compostion of urolith}

The composition of urinary stones varies with geographical location. The basic mineral compositions of urinary calculi are usually varies in different aniamls [34]. Silica, magnesium ammonium phosphate [phosphatic, struvite], calcium carbonate, and calcium oxylate are the most common types of crystals found in ruminants. Silica urolithiasis typically occurs in the western United States in animals that are grazing pastures or eating feeds harvested from pastures with high silicate concentrations [21]. Struvite uroliths [magnesium, ammonium or phosphorous] occur due to high grain feeding and low dietary calcium to phosphorous ration [35]. Struvite uroliths form when the urine become supersaturated with magnesium, ammonium or phosphorous and when urine $\mathrm{pH}$ is $>6.5$ [24]. The difference in susceptibility to struvite formation is due to magnesium oxide promoting the formation of alkaline urine whereas magnesium chloride promotes formation of acidic urine. In ruminants, silica urolithiasis is associated with high dietary calcium to phosphorous ratio, grazing on semiarid ranges; increased feed intake of silica and reduced water intake.

\section{Chemical analysis of calculi}

A better understanding of physiochemical principles underlying the formation of calculus has led to a need for the precise information on the chemical composition of uroliths [11]. Qualitative chemical tests provide only a rough indication of the relative amounts of different constituents in a mixed stone. A number of physical methods are used for the analysis of calculi including optical crystallography, X-ray diffraction, infrared spectroscopy, X-ray spectroscopy and thermo- 
gravimetry whereas chemical analysis remains the most convenient procedure to evaluate uroliths. The method is relatively rapid, detects minor components of mixed calculi and readily can be made quantitative. A method for the quantitative chemical analysis of urolith is described [15].

\section{Diagnostic imaging of urolithiasis}

Diagnosis is based on history, clinical signs, and physical examination. Making a diagnosis involves integrating findings from the signalment, history, physical examination, clinical signs, time course of the disease and urinary tract imaging [9]. However radiology \& ultrasonography may be required to differentiate patients with uroliths from urinary tract infections, granulomatous urethritis, prostatic disease and neoplasia.

Radiology: Uroradiology is an up-to-date, imageoriented reference in the style of a teaching file that has been designed specifically to be of value in clinical practice [36]. The modality of imaging chosen may include a combination of plain abdominal radiographs. Location of calculi can be determined by radiography [37]. Radiography helps in differentiating between different types of uroliths as their radio densities provide a clue to the stone type [15]. Multiple stone in urethra and urinary bladder can also be recorded by radiography.

Ultrasonography: Sonography is a non-invasive, reproducible and inexpensive method for diagnosis of urolithiasis, localization urethral calculi and rupture of urethra or the urinary bladder [38]. It is safer for both patient and the operator as it does not involve the use of ionizing radiation. If available, ultrasonography should be used as the primary diagnostic imaging tool although pain relief, or any other emergency measures should not be delayed by imaging assessments. It can identify stones located in the calices, pelvis, and pyeloureteric and vesicoureteric junctions, as well as upper urinary tract dilatation. For stones $>5 \mathrm{~mm}$, ultrasound has a sensitivity of $96 \%$ and specificity of nearly $100 \%$. For all stone locations, sensitivity and specificity of ultrasound reduces to $78 \%$ and $31 \%$, respectively [34]. The volume, size and shape of the urinary bladder can be detected by cystosonography [39], besides changes in the wall thickness, intraluminal defects and seat of calculi lodgement can be detected. Abdominal sonography is useful to evaluate the bladder [40] but is unrewarding for evaluation of the entire length of the urethra. It can detect small calculi, radiolucent calculi and bladder mass like polyps neoplasia [9], stones of 1 to $2 \mathrm{~mm}$ of diameter that can not be seen on X-ray, structures of varying size 1.50 to $2.7 \mathrm{~cm}$ floating in anechoic fluid [urine] in the urinary bladder with strong distal acoustic shadow can be detected. Scanning of bladder revels rounded to unevenly hyperechoic shadows with multiple spread tiny hyperechoic patterns [41].

\section{Treatment}

Various treatment modalities, both medical and surgical for the management of urolithiasis have been developed in almost all the species [26,28]. In ruminants, obstructive urolithiasis can be successfully treated if recognized early in the clinical course $[9,42$, 43]. In mild cases, the animals can be treated by using tranquilizers and antispasmodics [44], litholytic drugs like cystone. Diuresis should not be used before the removal of calculi and afterwards their administration is generally not required. Since there is hyperkalemia, hyponatremia and hypocalcaemia, therefore stabilization of such metabolic derangements often involves administration of intravenous fluids for several hours, with repeated assessment of hydration, acid-base balance and serum electrolyte concentrations. Such treatments occasionally involve concerns about exacerbation of bladder distention in animals with an intact bladder. The animals that shows raised levels of BUN and creatinine can be effectively treated by peritoneal dialysis $[25,45]$.

The treatment of obstructive urolithiasis is primarily surgical [46]. Recurrent urolithiasis, calculi at multiple sites, badly damaged urethra, atonic bladder or severe cystitis leads to failure of surgical repair in obstructive urolthiasis [26]. Urethrotomy, either post scrotal or post-ischial at the site of calculi lodgement is widely recommended and practiced to relieve the obstruction [8, 41]. However, postoperative leakage of urine from the site of obstruction leads to necrosis of urethra and subcutaneous tissues. Further, postoperative urethral constriction and recurrent urolithiasis are potential factors that results in the unfavorable outcome after urethrotomy, [26,47]. Other surgical methods include penile catheterization [48] cystotomy and bladder fistulation [44], intra pelvic cystic catheterization and peile amputation [48] and, tube cystotomy is in voyage. The technique of tube cystotomy is a method of fixation of tube in the urinary bladder for the free passage of urine, followed by chemical dissolution of calculi which shows excellent results.

Cystotomy tubes provide a practical method for the urinary diversion when more radical surgical procedures are not feasible [26]. Cystotomy tubes bypass urinary outflow obstructions or as an alternative to the urethral catheterization [49]. Several different types of tubes are available, including Foleys catheters, Mushroom tip catheters and percutaneous catheters; more recently low profile gastrostomy tubes have been adapted for the use in cystotomy tubes [26]. Cystotomy tubes should remain in place for at least 14 days before removal to ensure adequate adhesions between the bladder and the body wall to reduce the possibility of urine leakage or peritonitis [26]. Tube cystotomy is not free from complications and some complications involved are urine leakage, wound infection or dehiscence problems with the tube itself such as irritation at the stoma site, obstruction or accidental dislodgment and 
problems related to ascending infection due to the presence of the tube.

\section{Preventive measures}

Composition of uroliths together with environmental and dietary factors should be considered when establishing adequate preventive measures for urolithiasis [48]. Critical preventive measures such as providing calcium to phosphorous ratio of $2: 1$ in the complete ration, increasing the salt levels to 4 percent of the diet in order to stimulate water consumption and to increase urine volume and maintenance of adequate and abundant water supplies should be highly considered [51]. Struvite crystals can be prevented by the dietary modification to induce urine acidification . The ration should be modified, which includes elimination of alfaalfa feeding, reduction or elimination of grain feeding, a change to grass hay as primary forage, encouragement of grazing and ammonium chloride supplementation [52]. These modifications are intended to reduce the urinary load of calculogenic minerals, especially calcium and phosphorous through elimination of alfaalfa and grain feeding respectively. Besides potentially altering the mineral content of the diet, free access to grazing may increase the daily amount of water intake, which may in turn dilute urine, thus limiting calculogenesis. Changing from legume to grass hay and feeding ammonium chloride may move the dietary balance of strong cations and anions towards greater concentration of strong anions. Those areas where sheep exclusively are fed on paddy grasses in winters due to non availability of pastures, fortifi-cation of the dry paddy grass need to be undertaken to reduce the oxalate content of the grass [53]. Provision of clean water in multiple sites and intentional salting moistened grass hay, induction of diuresis and maintenance of dilute urine would help a long way keeping urolithiasis in check [54]. Screening of the animals be treated mandatory $[55,56]$ to categorize them as stone formers and non-stone formers before the disease is manifested clinically.

\section{References}

1. Smith, J.A. Divers, T.J and Lamp, T.N, (1989) Ruptured urinary bladder in a Post- parturient cow. Cornell Vet.73; 312.

2. Winter, R.B., Hawkins, L.L., Holterman, D.E and Jones, S.G. (1987) Catheterization- An effective method of treating bovine urethral calculi. Veterinary Medicine 82:1261-1266.

3. Kushwaha, R.B.; Amarpal; Kinjavdekar, P.; Aithal, H.P.; Pawde, A.M.; Pratap, K. (2009) Urolithiasis in buffalo calves: a review of 91 cases. Indian Journal of Veterinary Surgery vol.30 [1]: 9-12

4. Divers, T.J Reef. V.B and Roby. K.A (1989) Nephrolithiasis resulting in intermittent urethral obstruction in cow. Cornell Vet 79: 143.

5. Singh, J. and Singh, K. (1990) Obstructive Urolithiasis and Uraemia in Cattle and Buffaloes. A Review. Indian Journal Of Veterinary Surgery 11: 1-20.

6. Amarpal., Kinjavdekar, P., Aithal, H.P., Pawde, A.M., Tarunbir, Singh, Pratap, K. and Singh, T. (2004) Incidence of urolithiasis: a retrospective study of five years. Indian Journal of Animal Sciences 74[2]:175-177.
7. Muhee, A. (2006) Prevelance and clinical management of obstructive urolithiasis in cattle calves. M.V.SC Thesis submitted to Sher-e-Kashmir University of Agricultural Sciences and Technology of Kashmir, Shalimar, Srinagar.

8. Makhdoomi, D.M. (1994) Studies on intestinal obstruction in calves with emphasis on the role of species and electrolyte imbalance. Ph.D. Dissertation, CCS Haryana Agricultural Universtity, Hisar, [India].

9. Radostitis OM, Blood DC. Gray GC, and Hinchcliff KW (2005) Veterinary Medicine a text book of the disease of cattle, sheep, pig, goat and horse. Bailliere Tindall, London, pp. 1877.

10. Hesse AT, Tiselius H-G, Siener R., (2009) Urinary Stones, Diagnosis, Treatment and Prevention of Recurrence. 3rd edn. Basel, S. Karger AG. ISBN 978-3-8055-9149-2.

11. Unmack, A (2011) Constituents of calculi from the urinary tract of bulls and bullocks. Evidence of silica urolithiasis in cattle in Denmark. Kongelige Veterinaer- og Landboho iskol es Aarsskrift, 1963:1-12.

12. Lipismita Samal, Ashok Kumar Pattanaik, Chinmoy Mishra, Biswa Ranjan Maharana, Laxmi Narayan Sarangi, Rubina Kumari Baithalu, (2011) Nutritional stretegies to prevent Urolithiasis in Animals, Vet. World. 4[3]: 142-144.

13. Loreeti PA, Oliveria Lo, Cruz CF and Driemer D. (2003) Cinical and pathological study of an outbreak of obstructive urolithiasis in feedlot cattle in South Brazil, Pesq. Vet.Bras; 23 [2]; 223-236.

14. Clotide, E.M.P., Cappelaro, D.M., Nobre, D and Campedelli, P. (1980) Urolithiasis in bovines. Biologico, Sao. Panlo. 46 : 77-80.

15. Kannan KVA \& Lawrence KE (2010) Obstructive urolithiasis in a Saanen goat in New Zealand, resulting in a ruptured bladder $N Z$ Vet. J.58 [5]:269-271.

16. Honeck P, Wendt-Nordahl G, Krombach P, et al. (2009) open stone surgery still play a role in surgery still play a role in the treatment of urolithiasis. Data of a primary urolithiasis center. J Endourol 23[7]:1209-12.

17. Sharma, A.K.; Mohindroo, J.; Aithal, H.P. (2009) Physiological, urological changes and surgical management of urethal obstruction in bovine 25 cases [2001-2006]. $\mathrm{J} \mathrm{Am}$ Vet MedAssoc; 234:249-252.

18. Dusty W. Nagy (2009) Urolithiasis in small ruminants [Proceedings] CVC in Kansas City procedings.

19. David C and Van Metre (2010) urolithiasis in small ruminants [Proceedings], Cvc In Kansas City Proceedings.

20. Vengai Mavangira, Jennifer M. Cornish,John A. Angelos (2010) Effect of ammonium chloride supplementation on urine $\mathrm{pH}$ and urinary fractional excretion of electrolytes in goats Journal of the American Veterinary Medical Association, 237 (11): 1299-1304.

21. Jones ML, Streeter RN, Goad CL. (2009) Use of dietary cation anion difference for control of urolithiasis risk factors in goats. Am J Vet Res, 70:149-155.

22. Worcester EM, Coe FL (2010) Clinical practice. Calcium kidney stones. NEngl J Med. 363[10]:954- 63.

23. Pearle MS, Asplin JR, Coe FL, Rodgers A, Worcester EM (2008). Medical management of urolithiasis. In: 2nd International consultation on Stone Disease, Denstedt $J$, Khoury S. eds. pp. 57-84.

24. Straub M, Strohmaier WL, Berg W, (2012) Diagnosis and metaphylaxis of stone disease. World J Urol 2005 Nov; 23[5]:309-23.

25. Makhdoomi, D.M and Marudwar, S.S. (1992) Efficacy of peritoneal dialysis in reversal of uremic changes in bovine. Indian Journal of Veterinary Surgery 13:37-38.

26. Dubey,A., Pratap, K., Amarpal, Aithal, H.P., Kinjavdekar, P., Singh, T. and Sharma, M.C (2006) Tube Cystotomy and chemical dissolution of urethral calculi in goats. Indian Joaurnal Of Veterinary Surgery. 27[2]: 98-103.

27. Buchholz N, El-Husseiny T, Moraitis K, (2010) Long-term follow-up of recurrent stone-formers BJU Int Jan; 105[1]:1-2.

28. Janke JJ, Osterstock JB, Washburn KE, (2009) Use of 
Walpole's solution for treatment of goats with urolithiasis: 25 cases [2001-2006]. J Am Vet MedAssoc; 234:249-252.

29. Wolf,J (2011) Nephrolithisais: Acute Renal Colic, Medscape. Drug and disease procedures, Dept. of Urology, University of Michigan.

30. Gangwar, S.D., Pandey, N.N. and Celly, C.S. (1990) Clinico haematological profile of calves in experimental uraemia of post renal origin. Indian Vet. J. 67:645-648.

31. Jadon, N.S., Joshi, H.C; Singh, B and Kumar, A. (1989) Urological and biochemical changes in experimental urethral obstructions in buffalo calves. Indian Journal of veterinary Medicine $7: 49-51$.

32. Socket, D.C., Knight, A.P; Fettmaan, M.J., Kichi A.R., Smith, J.A and Arnold, S.M. (1986) Metabolic changes due to experimentally induced rupture of bovine urinary bladder. Cornell Vet. 76 198-212.

33. Berkow, R. (1998) The Merck Manual of Diagnosis and Therapy, edu 8. Merck Sharp and Dohme Research Laboratories 43: 232-258.

34. Basiri A, Ziaee AM, Kianian HR, et al. (2008) Ultrasonographic versus fluoroscopic access for percutaneous nephrolithotomy: A randomized clinical trial. J Endourol 22[2]:281-4.

35. Van Saun, R.J (2007) Urinary blockage in Hamas and alpacas. Lamalinle 8; 30- 31.

36. Sueng Hyup Kim (2012) Radiology Illustrated: Gynecologic Imaging: Gynecologic Imaging, Elsevier Science Health Science Division, pp. 1086-87.

37. Busk, R.L and Ackermann, N. (1986) Urinary System. In: Small animal Radiology and ultrasonography, edu 2 W.B Saunderss Company, Tokyo, P 644.

38. Braun, U. (1993) Ultrasonographic examination of the left kidney, the urinary bladder and the urethra in cows. Zentral blatt Vet. Med 40 (1): 1-9.

39. Khan AM, Makhdoomi D M and Suhani Bashir (2011) Surgical management of obstructive urolithiasis in a crossbred Jersey calf. Intas Polivet Vol. 12 No. 1 pp. 52-53.

40. Janene, K.,Kingston and Henry, R. Staempfli, (1995) Silica Urolithiasis in a male Ilama. Canadian.Veterinary. Journal. 36: 767-768.

41. Makhdoomi D.M and Shiekh G.N (2008) Diagnosis of obstructive urolithiasis in calves by Ultrasonography Journal of Remount Vety. Corps, 47 (1): 27-38.

42. Jennifer M, Ewoldt.Meredyth L,.Jones,Matt D, Miesner
(2008) Surgery of Obstructive Urolithiasis in Ruminants Veterinary Clinics of North America- food Animal Practice, 24(3): 455-465.

43. Elisa M. Ermilio, Mary C. Smith (2011) Treatment of Emergency Conditions in Sheep and Goats Veterinary Clinics of North America: Food Animal Practice, 27 (1): 3345.

44. Gasthuys, F., Steenhaut, M, De Moor, A, and Sercu, K (1993) Surgical treatment of urethral obstruction due to urolithiasis in male cattle. A review of 85 cases. Veterinary Record 20: 522-526.

45. Pawde AM, Gupta BB, Marudwar SS, Patil SN, and Dhakate MS. (1992) Efficacy of peritoneal dialysis in experimental peritonitis of of calves. Indian Journal of Veterinary Surgery 13:61-64.

46. Van Metre, D.C., House, J.K., Smith, B.P., George, L.W., Angelos, S.M, Angelos, J.A and Fecteau G. (1996) Obstructive urolithiasis in ruminants: Medical treatment and urethral surgery. Comp.cont.Educ. 18: 317-328.

47. Türk, T. Knoll, A. Petrik, K. Sarica, M. Straub, C. (2012) Guidelines on Urolithiasis, J. Endouroly, 15(7):671-3.

48. Winter, R.B., Hawkins, L.L., Holterman, D.E and Jones, S.G. (1987). Catheterization- An effective method of treating bovine urethral calculi. Veterinary Medicine 82: 1261-1266.

49. Kalim .M.O, Zaman,R and S k Tiwari (2011) Surgical Management of Obstructive Urolithiasis in a male Cow calf. Vet. World, 4(5): 213-214.

50. Teotia, G. (1975) Screening of calves as normal and stone formers. Veterinary Record 128: 234-238.

51. Jennings, P.B. (1984) Practice of Large Animal Surgery, W.B Saunders. Philadelphia, pp 1072.

52. Leonard, R.H and Butt, A.J.(1995) Qualitative identification of urinary calculi. Clin.Chem. 1:241-248.

53. kushwaha R.B, Gupta A.K, Dwivedi D.K, and Sharma Ankur (2011) Obstructive Urolithiasis in Small Ruminants and its Surgical management. Intas Polivet, 12 (2): 359-362.

54. Pathak, Rekha, Kushwaha, R. B., Kumar, Sanjay (2009) Clinicophysiological Effects of Intraspinal and Intramuscular Xylazine - Ketamine in Uremic Buffalo Calves The Indian Journal of Veterinary Research 18(1): 42- 45.

55. Maxwell Oli \& Oultram J.O., (2011) Urolithiasis, Livestock 16(5): $15-18$

56. Singh, Bhaskar, K. (1984) Pelvic site tapping of urinary bladder in bovine. Indian Vet. J. 66: 336-338.

$* * * * * * * *$ 